\title{
PRINCIPAIS SÍNDROMES ELETROCLÍNICAS DO LACTENTE: UMA REVISÁO DA LITERATURA
}

\author{
MAIN ELECTROCLINIC SYNDROMES OF THE INFANT: A LITERATURE \\ REVIEW
}

Bruno César Fernandes ${ }^{1}$, Raquel Borges de Barros Primo ${ }^{2}$, Anny Karoliny das Chagas Bandeira ${ }^{3}$, Mariella Rodrigues da Silva ${ }^{4}$, Carolina Calixto de Souza Andrade ${ }^{5}$

${ }^{1}$ Empresa Brasileira de Serviços Hospitalares-Hospital Universitário da Grande Dourados, Dourados, Mato Grosso do Sul, Brasil.

${ }^{2}$ Universidade Federal da Grade Dourados - UFGD, Dourados, Mato Grosso do Sul, Brasil.

${ }^{3}$ Centro Universitário Jorge Amado, Salvador, Bahia, Brasil.

${ }^{4}$ Empresa Brasileira de Serviços Hospitalares-Hospital Universitário da Grande Dourados, Dourados, Mato Grosso do Sul, Brasil.

${ }^{5}$ Hospital Universitário Professor Edgard Santos-Hospital das clínicas, Salvador, Bahia, Brasil.

\section{RESUMO}

Uma síndrome eletroclínica (também conhecida como síndrome epiléptica) consiste em um conjunto de características que associam convulsóes, características de eletroencefalografia e de imagem que tendem a ocorrer juntas. Entre elas há um grupo que afeta lactentes, geralmente tendo etiologia genética. Objetivo: realizar uma revisão da literatura sobre os tipos mais comuns de síndromes eletroclínicas do lactente, descrevendo suas principais características. Metodologia: Trata-se de uma revisão narrativa da literatura de artigos publicados entres os anos de 2005 e 2020, nos idiomas português e inglês. A pesquisa foi realizada no mês de dezembro de 2020. Foram utilizados os seguintes descritores para a busca dos artigos: Síndromes eletroclínicas. Epilepsia. Lactente. Resultados:Através da pesquisa realizada foram selecionados 12 artigos científicos, sendo nove deles no idioma inglês e três no idioma português. Conclusão:O estudo identificou 7 síndromes eletroclínicas comuns nos lactentes e oportunizou concluir que o conhecimento do perfil clínico, dos tipos de crises e das características doeletroencefalografia do fenótipo da doença associado à mutação específica pode ajudar a melhorar a precisão e o gerenciamento do diagnóstico das síndromes eletroclínicas.

Descritores: Síndromes Epilépticas. Epilepsia. Lactente. 


\section{ABSTRACT}

An electroclinic syndrome (also known as epileptic syndrome) consists of a set of characteristics that associate with seizures, characteristics of electroencephalography and imaging that tend to occur together. Among them is a group that affects infants, usually having a genetic etiology. Objective: to carry out a literature review on the most common types of infant electroclinical syndromes, describing their main characteristics. Methodology: This is a narrative review of the literature of articles published between 2005 and 2020, in Portuguese and English. The research was carried out in December 2020. The following descriptors were used to search for the articles: Electroclinical syndromes. Epilepsy. Infant. Results: Through the research carried out, 12 scientific articles were selected, nine of them in English and three in Portuguese. Conclusion: The study identified 7 common electroclinical syndromes in infants and made it possible to conclude that knowledge of the clinical profile, types of crises and characteristics of the electroencephalography of the disease phenotype associated with the specific mutation can help improve the accuracy and management of the diagnosis of electroclinical syndromes.

Descriptors: Epileptic Syndromes. Epilepsy. Infant.

\section{INTRODUÇÁO}

Uma síndrome epiléptica (ou síndrome eletroclínica) refere-se a um conjunto de características que incorporam tipos de convulsóes, eletroencefalografia (EEG) e características de imagem que tendem a ocorrer juntas. Frequentemente, apresenta características dependentes da idade. Também pode ter comorbidades distintas, como disfunção intelectual e psiquiátrica, juntamente com achados específicos em estudos de EEG e de imagem. Pode ter implicaçóes etiológicas, prognósticas e de tratamento associadas, mas é importante ressaltar que a síndrome da epilepsia não tem uma correlação individual com um diagnóstico etiológico e serve a um propósito diferente, como orientar o tratamento ${ }^{1,2}$.

Uma crise epiléptica (CE) pode ser descrita como a expressão clínica de uma descarga anormal, excessiva, sincrônica, nos neurônios que se situam basicamente no córtex cerebral. Esta atividade paroxística é intermitente e geralmente autolimitada, durando de segundos a poucos minutos ${ }^{3}$. Quando prolongada ou recorrente é caracterizada como estado de mal epiléptico (EP) ${ }^{4}$. A epilepsia (ou convulsão) significa a repetição de duas ou mais CE não provocadas. O termo "não provocada" indica que a CE não foi causada por febre, traumatismo cranioencefálico, alteração hidroeletrolítica, transtornos tóxicos ou doença concomitante. Crises convulsivas provocadas são aquelas que acontecem na presença de circunstância específica, recorrendo, apenas, se a causa aguda permanece, não caracterizando epilepsia ${ }^{3}$.

Em outras palavras, síndromes epiléticas é um termo generalizado e significa uma doença crônica já está instalada. Tem como característica clínica principal, recorrentes 
crises epiléticas. Ou seja, as crises epiléticas são as manifestaçóes clínicas mais comuns das síndromes epiléticas. Ademais, as síndromes epiléticas são classificadas considerando o eixo topográfico (relacionado a localização, podendo ser generalizadas ou focal) e o eixo etiológico (idiopáticas, sintomáticas e criptogênicas) ${ }^{5}$.

As síndromes eletroclínicas de início precoce representam um desafio diagnóstico significativo e uma grande proporção de casos ainda permanece inexplicável6. Compreender as implicaçóes de um diagnóstico de síndrome específico ajuda a apoiar as famílias que são frequentemente sobrecarregadas pelo diagnóstico de epilepsia em seus filhos ${ }^{7}$.

Uma série de síndromes de epilepsia se desenvolve na infância, e a identificação precisa do tipo de convulsão e a correlação com os achados do EEG fornecem importantes informaçóes prognósticas e de manejo para famílias com uma criança com epilepsia. Muitas síndromes de epilepsia na infância são prontamente tratadas e têm um excelente prognóstico. Portanto, o conhecimento das principais síndromes eletrolíticas no lactente bem como, das características clínicas dessas síndromes, aliado a um diagnóstico preciso e precoce pode melhorar o impacto psicossocial desses distúrbios nas crianças e em suas famílias ${ }^{7}$.

Diante do exposto, o objetivo desse estudo foi realizar uma revisão da literatura sobre os tipos mais comuns de síndromes eletroclínicas do lactente, descrevendo suas principais características.

\section{METODOLOGIA}

O estudo se desenvolveu por meio de uma revisão bibliográfica narrativa da literatura, cujos dados foram pesquisados em artigos científicos, que foram selecionados dos bancos de dados PubMed, Biblioteca Virtual em Saúde e Google Acadêmico, sendo selecionados artigos publicados entre os anos de 2005 e 2020, nos idiomas português e inglês.

\section{RESULTADOS E DISCUSSÃO}

Na pesquisa realizada, foram selecionados 12 artigos científicos, sendo nove deles no idioma inglês e três no idioma português.

O quadro 1 apresenta uma síntese das síndromes eletroclínicas do lactente mais comuns e suas principais características, tendo como embasamento dados extraídos do estudo de Perrine Plouin ${ }^{8}$. 
Quadro 1. Características clínicas e eletroencefalográficas nas Síndromes Eletroclínicas no Lactente

\begin{tabular}{|c|c|}
\hline $\begin{array}{l}\text { SINDROMES ELETROCLÍNICAS DO } \\
\text { LACTENTE }\end{array}$ & CARACTERISTICAS E MANIFESTAÇÓES CLÍNICAS ESPECIFICAS \\
\hline Epilepsia familiar benigna do lactente & $\begin{array}{l}\text { Sua manifestação clínica consiste em espasmos epilépticos, crises mioclônicas, } \\
\text { crises focais, crises tônicas generalizadas, crises tônico-clônicas generalizadas } \\
\text { (TCGs) e ausências. Espasmos epilépticos consistem em contrações axiais } \\
\text { que podem ocorrer em flexão, extensão ou ambos, podendo ser simétricos } \\
\text { ou assimétricos. A assimetria pode envolver os membros, a cabeça e o } \\
\text { videoeletroencefalografia (VEEG) geralmente é necessária para análise detalhada. } \\
\text { As contraçóes são breves e ocorrem em clusters (em conjunto) e duram cerca } \\
\text { de } 1 \text { a } 2 \text { segundos, alcançando o seu máximo mais lentamente do que a crise } \\
\text { mioclônica e mais rapidamente que a crise tônica. }\end{array}$ \\
\hline Epilepsia mioclônica do lactente (EML) & $\begin{array}{l}\text { Movimentos involuntários, rápidos, arrítmicos e abruptos. Os músculos que } \\
\text { geralmente se movem são os da regiâo cervical, braços e ombros e podem provocar } \\
\text { extensão ou flexão. Podem se manifestar de forma leve ou intensa, simétrica ou } \\
\text { nâo, envolvendo o corpo inteiro ou de forma regional ou localizada. Pode haver } \\
\text { alteraçáo da consciência. Crise tônicas ou de ausências nunca são observadas. As } \\
\text { mioclonias representam o único tipo de crise, exceto pela presença de crises febris } \\
\text { ou raras crises TCGs na adolescência }\end{array}$ \\
\hline Epilepsia benigna do lactente & $\begin{array}{l}\text { Os principais sinais clínicos são crises de clonias oculares, das pálpebras, } \\
\text { desvio da cabeça e dos olhos, clonias unilaterais, movimentos do corpo, parada } \\
\text { comportamental e hipertonia uni ou bilateral }\end{array}$ \\
\hline Síndrome de West & $\begin{array}{l}\text { Apresenta a seguinte tríade: espasmos infantis, hipsarritmia e parada ou regressão } \\
\text { do desenvolvimento. Caracteriza-se por padrão eletrográfico interictal composto } \\
\text { de ondas lentas e espículas de projeção anárquica e de elevada voltagem, duraçáo } \\
\text { e localização extremamente variáveis, praticamente contínua e, na maioria das } \\
\text { vezes, presente tanto em vigília quanto em sono. Podem existir espasmos com } \\
\text { anormalidades focais do EEG, } \\
\text { evoluindo com epilepsia parcial com ou sem hipsarritmia. }\end{array}$ \\
\hline $\begin{array}{c}\text { Epilepsia do lactente com crises focais } \\
\text { migratórias }\end{array}$ & $\begin{array}{l}\text { Ocorrem entre } 24 \text { dias e } 10 \text { meses (média aproximadamente } 4,5 \text { meses), sendo } \\
\text { quase contínuas, evoluindo com deterioraçáo clínica e alternando com períodos } \\
\text { livres de crises. Há boa correlação eletroclínica de acordo com a topografia das } \\
\text { descargas e complexa combinaçáo de crises focais simultâneas, podendo afetar um } \\
\text { único hemisfério durante vários meses, e sem o VEEG, as crises frequentemente } \\
\text { são despercebidas. Durante o período de } 1995 \text { a } 2005,27 \text { casos foram relatados; } \\
\text { na maioria dos casos recentes, o prognóstico tem sido menos grave, embora as } \\
\text { crises sejam intratáveis ao longo de alguns meses. }\end{array}$ \\
\hline $\begin{array}{c}\text { Encefalopatia mioclônica em distúrbios } \\
\text { não progressivos }\end{array}$ & $\begin{array}{l}\text { Subtipo da EML. Ocorre durante o primeiro ou segundo anos de vida, em uma } \\
\text { criança normal, que frequentemente tem história familiar de epilepsia ou crises. } \\
\text { As crises caracterizam-se por serem frequentes, breves, geralmente simétricas, } \\
\text { isoladas ou agrupadas em clusters, envolvendo a musculatura axial do corpo e os } \\
\text { membros, exacerbadas pela sonolência. }\end{array}$ \\
\hline Síndrome de Dravet & $\begin{array}{l}\text { A síndrome de Dravet ou epilepsia mioclônica grave do lactente ocorre } \\
\text { em criança previamente normal, que pode ter apresentado crise febril, uni } \\
\text { ou bilateral antes de } 1 \text { ano de idade. Ocorrem mioclonias maciças durante o } \\
\text { segundo e o terceiro ano de vida, deterioraçáo mental progressiva, evoluindo } \\
\text { frequentemente para estado de mal epiléptico e epilepsia refratária. As mioclonias } \\
\text { ocorrem preferencialmente ao despertar, ou precedendo uma crise TCG, são } \\
\text { geralmente agrupadas, predominantemente axiais, e podem provocar queda } \\
\text { ao solo e arremesso ao chão de objetos das mãos. Podem ocorrer mioclonias } \\
\text { erráticas distais em repouso, que são exacerbadas pelos movimentos }\end{array}$ \\
\hline
\end{tabular}

No ano de 1983, em Marselha, na França, foi realizado uma convenção internacional com o intuito de discutir e classificar as crises e síndromes eletroclínicas (epilépticas). Antes disso, ainda nos anos de 1970, já havia relatos de algumas síndromes eletroclínicas do lactente, entre elas a epilepsia mioclônica precoce (EMP), a encefalopatia epiléptica precoce do lactente (EEPL) e a síndrome de Ohtahara (de início neonatal). $\mathrm{Na}$ 
época, havia alguns aspectos importantes nessa seara, pois era incomum a realização da videoeletroencefalografia (VEEG) e, também, não se fazia uso de eletrodos musculares. Sendo assim, não havia como diferenciar ou classificar as crises epilépticas pelo traçado, e nem havia exames de imagem disponíveis para isso, como a tomografia computadorizada de crânio e/ou a ressonância nuclear magnética ${ }^{8}$.

Dessa forma, a única maneira para caracterizar as crises epiléticas era a anamnese. Para realizara classificação de uma síndrome eletroclínica é necessário pormenorizar sua semiologia, pois apenas dessa forma se compreende melhor a doença do paciente. Outrora, era comum que os pais apenas descrevessem as características mais exuberantes relacionadas as crises, o que levava o clínico a classificar sua maioria como generalizadas, contudo, quando se fazia a avaliaçáo por meio da VEEG, se constatava que na verdade, a maioria se tratava se crise focal ${ }^{8,9,10}$.

Pesquisadores fizeram uma análise de 90 neonatos que foram avaliados por VEEG durante três horas, sendo observado que o período no qual existe maior risco de desenvolver a primeira crise é em sua primeira semana de vida, tendo sido verificado que 76 crianças pertencentes a esse grupo estudado apresentaram crises. Com isso, se acredita que as crises nesse período da vida ocorrem em consequência da transição que é feita do sistema gabaérgico (de excitatório a inibitório), apesar de ainda não se saber exatamente quando isso ocorre8. Nessa populaçáo do estudo citado foram descritos casos com a síndrome de Ohtahara (7 casos), EMP (5 casos) e, ainda, 2 casos de crises neonatais familiares benignas (CNFBs), 2 de crises neonatais não familiares benignas (CNNFBs) e 2 de epilepsia com crises parciais migratórias do lactente ${ }^{8}$.

A etiologia das epilepsias é dividida em seis subgrupos, selecionados por causa de suas potenciais consequências terapêuticas. Uma nova terminologia foi introduzida, como encefalopatia epilética e de desenvolvimento. O termo benigno foi substituído pelos termos autolimitado e responsivo a medicamentos, para uso onde apropriado ${ }^{2}$.

A respeito dessa classificação das síndromes eletroclínicas, Schefferet et al. ${ }^{2}$ descrevem os seis tipos de etiologias: 1) Estrutural: que é quando uma anormalidade estrutural tem um risco substancialmente aumentado de ser associada à epilepsia (ex: anormalidades visíveis na neuroimagem estrutural); 2) Genética: resulta diretamente de uma mutação genética, na qual as convulsóes são um sintoma central do distúrbio; 3) Infecciosa: quando a epilepsia ocorre como resultado de uma infecção (ex: meningite ou encefalite);4) Metabólica: resulta diretamente de um distúrbio metabólico conhecido ou presumido no qual convulsóes são um sintoma central do distúrbio (ex: porfiria, uremia, aminoácido-acidopatias ou convulsões dependentes de piridoxina);5) Imune: quando as convulsóes são derivadas de inflamação do sistema nervoso central mediada por autoimunidade; 6) Desconhecida: quando a causa da epilepsia ainda não é conhecida. Nessa categoria, não é possível fazer um diagnóstico específico além da semiologia 
eletroclínica básica, como a epilepsia do lobo frontal. Ademais, a extensão em que uma causa pode ser encontrada depende da extensão da avaliação disponível para o paciente.

As síndromes eletroclínicas mais comuns que podem acometer as crianças no período neonatal são: 1) Epilepsia familiar beninga neonatal; 2) Síndrome de Ohtahara; 3) Encefalopatia mioclônica precoce. $\mathrm{Na}$ fase lactente: 1) Epilepsia familiar benigna do lactente; 2) Epilepsia benigna do lactente; 3) Epilepsia mioclônica do lactente; 4) Síndrome de West; 5) Epilepsia do lactente com crises focais migratórias; 6) Encefalopatia mioclônica em distúrbios não progressivos; 7) Síndrome de Dravet. Na infância: 1) Síndrome de Panayiotopoulos; 2) Crises febris plus (porém essas podem começar no lactente); 3) Epilepsia com crises mioclônico atônicas (previamente astáticas); 4)Epilepsia occipital da infância de início tardio (tipo Gastaut); 5) Epilepsia autossômica-dominante noturna do lobo frontal; 6) Epilepsia benigna com descargas centrotemporais; 7) Epilepsia com ausências mioclônicas; 8)Síndrome de Landau-Kleffner; 9) Encelalopatia epiléptica com espícula-onda contínua durante sono; 10) Síndrome de Lennox-Gastaut; 11) Epilepsia ausência da infância ${ }^{11}$.

O diagnóstico preciso é, muitas vezes, difícil, e a maioria dos pacientes passa por muitas investigaçôes, incluindo imagens cerebrais e testes neurofisiológicos, sanguíneos, líquido cefalorraquidiano e urina e, às vezes, testes mais invasivos, como biópsias hepáticas e musculares ${ }^{1,12,13}$.

Alguns podem até ter enfrentado a cirurgia de epilepsia com benefícios variáveis e, mais tarde, receberam um diagnóstico genético, que, se já fosse conhecido anteriormente, poderia ter afetado a decisão de prosseguir com a cirurgia. Encontrar uma causa pode salvar a família de mais angústia e a criança de investigaçóes em andamento. Com um diagnóstico, a família pode passar a aprender sobre a doença, suas comorbidades e implicaçôes prognósticas, o que permite planejar os cuidados de longo prazo de seus filhos e o acesso precoce a serviços e terapias ${ }^{13}$.

As classificações de crises epilépticas e epilepsias passaram a ser documentadas pela Liga Internacional contra a Epilepsia (International League Against Epilepsia, ILAE) na década de 1960, o que gerou as Classificaçôes que foram mais utilizadas até poucos anos atrás, que são as Classificações de 1981 e 1989. De acordo com essas classificaçóes, as crises eram divididas em focais ou generalizadas, de acordo com sua forma de início, ou em uma região específica no cérebro ou bilateral. A etiologia das epilepsias era, então, considerada idiopática, sintomática ou criptogênica ${ }^{11}$.

Assim, as síndromes eletroclínicas podiam ser classificadas conforme sua localização (ou seja, focais ou generalizadas), sua etiologia (como idiopáticas ou não idiopáticas) e pela idade de surgimento. Contudo, as epilepsias focais sintomáticas ou criptogênicas, como as ocasionadas por displasias corticais, podem aparecer em qualquer idade sem que se soubesse o motivo. Aqueles pacientes inseridos no grupo das epilepsias focais 
apresentam somente crises focais, enquanto aqueles no grupo das generalizadas podem apresentar tanto crises focais como generalizadas ${ }^{8}$.

Com o passar dos anos e devido aos avanços tecnológicos que surgiram, como o VEEG, que permitiu um melhor conhecimento das manifestaçóes ictais (ou seja, as manifestações das crises convulsivas), novas propostas de classificação começaram a ser divulgadas pela ILAE, no início do séc. XXI, culminando em inovaçóes no conhecimento em áreas de imagem e de genética molecular. A partir da publicação deste documento, inúmeros aspectos nosológicos passaram a ser discutidos pela comunidade científica em relação a esta área da epilepsia ${ }^{11}$.

Estudo conduzido por Amy McTague et al13 concluiu que

"Com a revolução molecular, o número de determinantes monogênicos conhecidos subjacentes às encefalopatias epilépticas cresceu rapidamente. Mutações dominantes de novo são frequentemente identificadas; mosaicismo somático e distúrbios recessivos também são vistos. Vários genes podem causar uma síndrome eletroclínica e, inversamente, um gene pode estar associado à pleiotropia fenotípica. Diversas causas genéticas e vias moleculares foram implicadas, envolvendo canais de íons e proteínas necessárias para a sináptica, regulação, e funções de desenvolvimento. A descoberta do gene fornece a base para percepçóes neurobiológicas, muitas vezes mostrando a convergência de caminhos mecanísticos. Essas descobertas sustentam o desenvolvimento de terapias direcionadas, que são essenciais para melhorar o resultado dessas doenças devastadoras.”

Com isso, a Classificação das Epilepsias da ILAE foi atualizada para refletir o ganho no entendimento das epilepsias e seus mecanismos subjacentes, seguindo os principais avanços científicos que ocorreram desde a última classificação ratificada em 1989. Como ferramenta crítica para o clínico praticante, a classificação da epilepsia deve ser relevante e dinâmica conforme as mudanças de pensamento científico, além de robusta e traduzível para todas as áreas do planeta. O principal objetivo da ferramenta é o diagnóstico de pacientes, a pesquisa sobre a doença, o desenvolvimento de terapias antiepilépticas e a comunicação em todo o mundo².

A nova classificação se origina de um projeto de documento enviado para comentários do público em 2013, que foi revisado para incorporar amplo feedback da comunidade internacional de epilepsia em várias rodadas de consulta. Apresenta três níveis, começando pelo tipo de convulsão (focal, generalizada, combinada e grupo de epilepsia desconhecido), em que assume que o paciente está tendo convulsóes epilépticas, conforme definido pela nova Classificação de Convulsóes ILAE de 2017. Após o diagnóstico do tipo de convulsão, o próximo passo é o diagnóstico do tipo de epilepsia, incluindo epilepsia focal, epilepsia generalizada, epilepsia generalizada e focal combinada e, também, um grupo desconhecido de epilepsia ${ }^{2}$.

O terceiro nível é o da síndrome eletroclínica, onde um diagnóstico sindrômico específico pode ser feito. A nova classificação incorpora a etiologia ao longo de cada 
estágio, enfatizando a necessidade de considerar a etiologia em cada etapa do diagnóstico, pois muitas vezes traz implicações significativas no tratamento ${ }^{2}$.

Há um grupo de síndromes eletroclínicas da infância que são chamadas de encefalopatias epilépticas, caracterizadas por crises clínicas recorrentes e descargas epileptiformes interictais proeminentes, vistas durante o período infantil inicial, estando associadas ao comprometimento do desenvolvimento cognitivo, sensorial e motor. Aproximadamente $40 \%$ das crises ocorrem durante os primeiros 3 anos de vida. Embora as encefalopatias epilépticas estejam principalmente associadas a defeitos estruturais do cérebro e distúrbios metabólicos herdados, as mutações genéticas patogênicas, também podem estar envolvidas em no desenvolvimento desta doença, mesmo quando não existem padrôes de herança genética ou consanguinidade claros ${ }^{1}$.

As encefalopatias epilépticas mais comuns são a síndrome de Ohtahara, encefalopatia mioclônica precoce, epilepsia da infância com crises focais migratórias, síndrome de West e síndrome de Dravet, que geralmente não respondem ao medicamento antiepilético tradicional. Muitos dos diagnósticos descrevem o fenótipo dessas síndromes eletroclínicas, mas não as causas subjacentes. Até o momento, aproximadamente 265 genes foram definidos na epilepsia e vários genes, incluindo STXBP1, ARX, SLC25A22, KCNQ2, CDKL5, SCN1A e PCDH19, foram associados a encefalopatias epilépticas precoces, e muitos desses genes estão potencialmente envolvidos no desenvolvimento e na função cerebral ${ }^{1}$.

\section{CONCLUSÓES}

Este estudo permitiu aos autores delinear as Síndromes Eletroclínicas mais comuns nos lactentes bem como, descrever suas principais características clínicas. Ao pesquisar sobre as síndromes eletroclínicas do lactente verifica-se que são uma condição que causa muito desalento e preocupação para os pais, sendo fundamental o conhecimento das características das Síndromes aliado a um diagnóstico preciso e precoce. Atualmente, os dados sobre a etiopatogenia e a base genética de algumas dessas síndromes tem sido progressivamente aprimorada e ampliada, e a detecção dos genes responsáveis se traduz em importância no tratamento do distúrbio e na seleção da terapia. Além disso, o prognóstico das doenças pode ser melhor estimado e ajudar a identificar famílias que podem se beneficiar de um encaminhamento para aconselhamento genético.

O conhecimento do perfil clínico, dos tipos de crises e das características do EEG do fenótipo da doença associado à mutação específica pode ajudar a melhorar a precisão e o gerenciamento do diagnóstico. Nos casos em que os achados eletroclínicos se mostrarem obscuros, painéis genéticos direcionados para epilepsia seriam uma alternativa econômica ao sequenciamento de genes individuais para o diagnóstico genético da síndrome. 
Afinal, a descoberta de genes fornece a base para insights neurobiológicos, geralmente mostrando convergência de vias mecanicistas, e esses achados sustentam o desenvolvimento de terapias direcionadas, essenciais para melhorar o resultado desses distúrbios devastadores.

\section{REFERÊNCIAS}

1. Gürsoy S, Erçal D. Diagnostic approach togenetic causes ofearlyonsetepilepticencephalopathy. J.Chil. Neurol. 2016; 31 (4) : 523-32.https://doi. org/10.1177/0883073815599262.

2. Scheffer IE, Berkovic S, Capovilla G, Connolly MB, French J, Guilhoto L, Hirsch E, Jain S, Mathern GW, Moshé SL, Nordli DR, Perucca E, Tomson T, Wiebe S, Zhang YH, Zuberi SM. ILAE classificationoftheepilepsies: Position paperofthe ILAE Commission for classificationandterminology. epilepsia. 2017;58(4):512-521. https:// doi.org/10.1111/epi.13709.

3. Ivares-da-Silva CR, Cardoso IS, Machado NR. Consideraçóes sobre epilepsia. BolCientPediatr. 2013;2(3):71-76. Acesso em: 05 jan 2021. Disponível em: https:// www.sprs.com.br/sprs2013/bancoimg/140324183248bcped_13_03_02.pdf.

4. Fisher RS, Acevedo C, Arzimanoglou A, Bogacz A, Cross JH, Elger CE et al. ILAE Official Report: A practical clinical definition of epilepsy. Epilepsia. 2014 Apr;55(4):475-482. https://doi.org/10.1111/epi.12550.

5. Brasil. Ministério da Saúde. Portaria SAS/MS no 1319, de 25 de novembro de 2013. Protocolo Clínico e Diretrizes Terapêuticas Epilepsia. Acesso em: 24 jan 2021. Disponívelem:http://portalarquivos.saude.gov.br/images/pdf/2016/fevereiro/04/ Epilepsia---PCDT-Formatado--.pdf.

6. Allen NM, Conroy J, Shahwan A, Lynch B, Correa RG, Pena SD, McCreary D, Magalhães TR, Ennis S, Lynch SA, King MD. Unexplained early onset epileptic encephalopathy: Exome screening and phenotype expansion. Epilepsia. 2016;57(1):e12-17. https://doi.org/10.1111/epi.13250.

7. Carney P, Prowse MA, Scheffer IE. Epilepsysyndromes in children. AustFamPhysician. 2005;34(12):1009-1015. Acesso em: 03 jan 2021. Disponível em: https://pubmed.ncbi.nlm.nih.gov/16333482/.

8. Plouin P. Crises epilépticas em neonatos e lactentes. Epilepsia.org, maio 2017. Acesso em: $28 \mathrm{dez}$ 2020. Disponível em: https://bit.ly/2K10LH6.

9. Cooper MS, Mackay MT, Fahey M, Reddihough D, Reid SM, Williams K, Harvey AS. Seizures in Children With Cerebral Palsy and White Matter Injury. Pediatrics. 2017;139(3):e20162975. https://doi.org/ 10.1542/peds.2016-2975. 
10. Park JT, Shahid AM, Jammoul A. Common pediatricepilepsysyndromes. Pediatr Ann. 2015;44(2):e30-35.https://doi.org/10.3928/00904481-20150203-09.

11. Guilhoto LMFF. Revisão terminológica e conceitual para organização de crises e epilepsias: relato da Comissão da ILAE de Classificação e Terminologia, 20052009. Novos Paradigmas?. J. epilepsy clin. neurophysiol. [online]. 2011, vol.17, n.3,pp.100105.ISSN16762649.https://doi.org/10.1590/S1676264920110003005.

12. Chemaly N, Losito E, Pinard JM, Gautier A, Villeneuve N, Arbues AS, An I, Desguerre I, Dulac O, Chiron C, Kaminska A, Nabbout R. Early and longterm electroclinical features of patients with epilepsy and PCDH19 mutation. EpilepticDisord.2018Dec1;20(6):457-467.https://doi.org/10.1684/epd.2018.100.

13. McTague A, Howell KB, Cross JH, Kurian MA, Scheffer IE. The genetic landscape of the epileptic encephalopathies of infancy and childhood. Lancet Neurol. 2016 Mar;15(3):304-316. https://doi.org/10.1016/S1474-4422(15)00250-1.

Autor Correspondente: Bruno César Fernandes

E-mail: brunoanaisafernandes@gmail.com

Recebido em: 2020-12-02

Aprovado em: 2020-12-18 